\title{
INVESTIGACIÓN
}

Recibido: 15/04/2021 --- Aceptado: 06/07/2021 --- Publicado: 04/08/2021

\section{ANÁLISIS DE LOS FACTORES PREDICTIVOS DEL ABANDONO ESCOLAR TEMPRANO}

\author{
Analysis of the predictive factors about early school dropout
}

Iratxe Suberviola Ovejas: Universidad de La Rioja. España.

iratxe.suberviola@unirioja.es

\section{Cómo citar el artículo:}

Suberviola Ovejas, I. (2021). Análisis de los factores predictivos del abandono escolar temprano. Vivat Academia. Revista de Comunicación, 154, 25-52. http://doi.org/10.15178/va.2021.154.e1373

http://www.vivatacademia.net/index.php/vivat/article/view/1373

\section{RESUMEN}

Finalizado el año 2020, España sitúa su tasa de Abandono Escolar Temprano en el 16\%, lejos del indicador propuesto por la Unión Europea en el plan Estrategia Europa 2020 que fijaba un $10 \%$ de media en los países de la Unión Europea. La bibliografía determina que el fenómeno del Abandono Escolar Temprano debe ser abordado desde un análisis multidimensional puesto que en él están implicados factores personales, familiares, educativos, sociales y económicos. Partiendo de esta premisa, se realiza un exhaustivo análisis bibliográfico sobre los factores de incidencia del mismo, seleccionando un total de 89 estudios. A partir de este marco, se plantea un modelo de análisis profundo y global de los aspectos que influyen en la intención del alumnado de abandonar la formación reglada de forma prematura Para ello, se realiza una adaptación del modelo UTAUT (Unified Theory of Acceptance and Technology), teniendo en cuenta las características propias de nuestro objeto de estudio. El objetivo último es dotar de un modelo de análisis para determinar aquellos factores predictivos que pueden desembocar en el Abandono Escolar Temprano, que, por un lado, constituya el germen de futuras investigaciones sobre esta temática y, por otro lado, posibilite realizar una intervención socio-educativa preventiva que haga descender dicha tasa.

PALABRAS CLAVE: Abandono Escolar Temprano - UTAUT - Deserción escolar Estrategia Europa 2020 - Teoría Unificada de Aceptación Tecnológica. 


\begin{abstract}
At the end of 2020, Spain has an Early School Dropout rate of $16 \%$. This percentage is far from the $10 \%$ proposed by the Europe 2020 Strategy for the countries of the European Union. The bibliography determines that fact of early school dropout must be approached from a multidimensional analysis because it involves personal, educational, social, economic factors, etc. With this in mind, we are an exhaustive bibliographic analysis is carried about the factors involved, selecting a total of 89 studies. From this, we propose a global model for the analysis of the aspects about influence students to leave their studies prematurely. To do this, we adapt the UTAUT (Unified Theory of Acceptance and Technology) model, To do this, we adapt the UTAUT (Unified Theory of Acceptance and Technology) model, to adapt it to our research problem. The main objective is to determine those predictive factors that produce early school dropout to carry out a preventive socio-educational intervention and reduce this rate.
\end{abstract}

KEYWORDS: Early School Dropout - UTAUT - Premature School Dropout - Europe 2020 Strategy - Unified Theory of Acceptance and Technology.

\title{
ANÁlISE DOS FATORES PREDITIVOS DO ABANDONO ESCOLAR PRECOCE
}

\section{RESUMO}

Finalizado o ano de 2020, a Espanha situa sua taxa de abandono escolar precoce em $15 \%$, longe do indicador proposto pela União Europeia no plano: Estratégia Europa 2020 que fixava em 10\% de média nos países da União Europeia.

A bibliografia determina que o fenômeno de abandono escolar precoce deve ser abordado desde uma análise multidimensional, devido a que estão implicados fatores pessoais, familiares, educativos, sociais e econômicos. Partindo desta premissa, se fez uma exaustiva análise bibliográfica sobre os fatores de incidência do mesmo, selecionando um total de 89 estudos. A partir deste marco, se levanta um modelo de análise aprofundado e global de aspetos que influenciam na intenção dos alunos de abandonar a graduação de forma precoce, para isto se realiza uma adaptação do modelo UTAUT(Unified Theory of acceptance and technology), tendo em conta as características próprias do nosso objeto de estudo. O objetivo final é proporcionar um modelo de análise para determinar os fatores preditivos que possam evoluir em abandono escolar precoce, que por um lado, constitua o início de futuras pesquisas sobre esta temática e pelo outro lado, possibilita realizar uma intervenção sócioeducativa preventiva que faça com que diminua a taxa.

PALAVRAS CHAVE: Abandono Escolar Precoce - UTAUT - Deserção escolar Estratégia Europa 2020 - Teoria Unificada de Aceitação Tecnológica. 


\section{INTRODUCCIÓN}

Con los datos de la Encuesta de Población Activa (en adelante EPA) publicado en enero de 2021 se ha conocido que la tasa de Abandono Escolar Temprano (en adelante AET) de España se sitúa en un 16\% (INE, 2020), superando el índice fijado por la Unión Europea en la Estrategia Europa 2020 que estipulaba para España un máximo del 15\% y un 10\% como media de los países miembros (Europan Commisión, 2020). La tasa de AET, en el caso español, se concreta en un indicador estadístico que sigue las indicaciones y metodología de cálculo de Eurostat. Además, en nuestro país, este indicador forma parte del sistema estatal de indicadores de la educación del Instituto Nacional de Evaluación Educativa (INEE), organismo dependiente del Ministerio de Educación, Cultura y Deporte (MECD), encargado de la evaluación del sistema educativo español, así como de la monitorización del progreso de los objetivos del marco estratégico Educación y Formación 2020. En lo que al indicador se refiere, se define como la proporción de personas de entre 18 y 24 años que presenta un nivel de educación alcanzado máximo de Educación Secundaria de primera etapa y que declara no haber recibido ningún tipo de educación o formación en las cuatro semanas previas a la realización de la EPA (Carrasco, et al., 2015; INE, 2020).

El objetivo final de las reformas estructurales es cambiar o modificar, totalmente o en parte, los fundamentos o bases esenciales del sistema en los ámbitos económico, social e institucional. Dentro de las reformas estructurales, como la Estrategia Europa 2020, las políticas educativas conforman un pilar básico, ya que tienen un impacto directo en el desarrollo socioeconómico de los países y en la integración social de sus ciudadanos. Por ello, se crea una comisión denominada Educational and training 2020 como instrumento marco para la cooperación europea en educación y formación que proporciona objetivos estratégicos comunes para los países miembros de la U.E., incluyendo un conjunto de principios para lograr dichos objetivos, así como métodos de trabajo comunes y los indicadores de seguimiento (European Commision, 2020), entre los que se encuentran de forma preferente la reducción de la tasa de AET.

Comprender el problema AET lleva consigo acercarse a esta problemática desde un marco de análisis amplio y global, puesto que en él confluyen dimensiones del ámbito social, económico, educativo, personal y familiar (Choi de Mendizabal y Calero, 2013; Marchesi, 2003; Nevala y Hawley, 2011; Rizo y Hernández, 2011). Es evidente que una alta formación, puede genera toda una serie de resultados positivos relacionados con el empleo, sueldos más altos, mejor salud, menor delincuencia, mayor cohesión social, menor gasto público y social y, mayor productividad y crecimiento. Por el contrario, un inadecuado nivel educativo, resultado del AET tiene altos costes para el individuo, para la sociedad y para la economía (Psacharopoulos,2007; Belfield, 2008; Nevala y Hawley, 2011). Paliar esta situación a través del descenso de la tasa de AET se torna necesario para el desarrollo social y económico de cualquier país. Por ello, es de suma importancia que el ámbito educativo sea conocedor de los factores que subyacen para que un determinado alumno o alumna tome la decisión de abandonar los estudios de

Vivat Academia. Revista de Comunicación. 2021, nº 154, 25-52 
forma prematura, puesto que desde el paradigma de una educación compensatoria se pueden adoptar acciones profilácticas que minimicen el efecto producido por los factores de riesgo evitando un futuro AET (Montes y Parcerisa, 2016).

Partiendo de las directrices marcadas por el proyecto Europa 2020 en torno a la necesidad de reducir la Tasa de AET como un objetivo prioritario, proponemos un modelo de análisis de los factores determinantes del mismo. Para ello, se lleva a cabo un exhaustivo análisis bibliográfico que nos permita determinar las dimensiones que se sitúan en la trastienda del AET (Alemany et al., 2013; Camacho, 2018; Cerdá, et al., 2020; Choi de Mendizabal y Calero, 2013; Constante-Amores, et al., 2021; GonzálezPienda, 2003; González-Rodríguez, et al., 2016; Marchesi, 2003; Mena et al., 2010; Rizo y Hernández, 2019; Rodríguez Pienda y Zamora, 2021; Romero y Hernández, 2018; Sánchez-Alhambra, 2017; Subirant, 2006, entre otros). A partir de ello se realiza una categorización de dichas dimensiones; dimensión personal, dimensión del contexto familiar, dimensión social y dimensión del sistema educativo.

Nuestra propuesta de análisis parte de la idea de que el AET es una acción que se sitúa dentro del conjunto de conductas y comportamientos de las personas, por lo que se realiza un recorrido por los diferentes modelos explicativos de la misma, determinando que el modelo UTAUT (Ventastekt, et al., 2003) constituye una buena base para el análisis multidimensional del AET, puesto que se trata una teoría explicativa de la conducta orientada hacia una determinada acción que ha sido ampliamente contrastada y utilizada como modelo explicativo de ciertas conductas y comportamientos humanos (Bing, 2013; Oye, et al., 2014; Raza et al., 2020; Salloum y Shaalan, 2019). Partiendo de la estructura base de dicho modelo, se realiza una adaptación de este para dar cabida a aquellos aspectos recabados en el análisis bibliográfico, que va a desembocar en un modelo explicativo global y multidimensional del AET con un enfoque integrador.

El planteamiento de análisis de los factores de riesgo del AET que se presenta a continuación forma parte de un estudio más amplio en el que a partir de mismo se desarrolla un cuestionario ad-hoc para la recogida y posterior análisis de datos.

\section{MARCO TEÓRICO. FACTORES PREDICTIVOS DEL ABANDONO ESCOLAR TEMPRANO}

El elevado nivel de AET es un motivo de preocupación creciente y permanente desde hace varias décadas, siendo uno de los principales problemas a los que tiene que enfrentarse el sistema educativo español. De cara a reducir esta tasa es primordial determinar los factores subyacentes que convergen detrás de la misma, ya que esto permitiría al sistema educativo desplegar unas estrategias de actuación preventivas que reduzcan la intención de los alumnos de abandonar la formación reglada antes de los 18 años. Actualmente no existe en los centros educativos un protocolo establecido ni sistémico que establezca las intervenciones a desarrollar en la contienda con el Abandono Escolar Temprano (Sánchez-Alhambra, 2017). 
En la bibliografía podemos encontrar un gran número de estudiosos que analizan los factores que determinan el AET (Alemany et al., 2013; Camacho, 2018; Cerdá, et al., 2020; Choi de Mendizabal y Calero, 2013; Constante-Amores, et al., 2021; GonzálezPienda, 2003; González-Rodríguez, et al., 2016; Marchesi, 2003; Mena et al., 2010; Rizo y Hernández, 2019; Rodríguez Pienda y Zamora, 2021; Romero y Hernández, 2018; Sánchez-Alhambra, 2017; Subirant, 2006). Tras la realización de un exhaustivo análisis de los mismos se puede determinar que el fenómeno del AET presenta un carácter multidimensional, con factores interrelacionados. Desde esta concepción, los factores predictivos se pueden categorizar en cuatro grandes dimensiones que podemos observar en la siguiente tabla.

Figura 1. Dimensiones del abandono escolar temprano

\begin{tabular}{|c|c|c|}
\hline \multirow{2}{*}{$\begin{array}{l}\text { Dimensión } \\
\text { personal }\end{array}$} & $\begin{array}{l}\text { Factores biopsicosociales } \\
\text { del individuo }\end{array}$ & $\begin{array}{l}\text { Género, capacidad cognitiva, competencia } \\
\text { percibida, autoestima, motivación, } \\
\text { autoconcepto, ansiedad, perseverancia, estilos } \\
\text { de aprendizaje, tolerancia a la frustración, } \\
\text { satisfacción inmediata, consumo de sustancias, } \\
\text { abuso de videojuegos, falta de sueño. }\end{array}$ \\
\hline & $\begin{array}{l}\text { Factores referentes a la } \\
\text { relación individuo- } \\
\text { ámbito educativo }\end{array}$ & $\begin{array}{l}\text { Rendimiento académico, historia escolar, } \\
\text { absentismo, técnicas y hábitos de estudio, } \\
\text { repetición de curso, desfase curricular, } \\
\text { bullying. }\end{array}$ \\
\hline \multirow{2}{*}{$\begin{array}{l}\text { Dimensión del } \\
\text { contexto } \\
\text { familiar }\end{array}$} & $\begin{array}{l}\text { Factores psicosociales de } \\
\quad \text { la familia }\end{array}$ & $\begin{array}{l}\text { Clase social, nivel de estudios de los padres, } \\
\text { recursos económicos, incorporación al mercado } \\
\text { laboral, lengua materna, país de origen. }\end{array}$ \\
\hline & $\begin{array}{l}\text { Factores referentes a la } \\
\text { relación familia-ámbito } \\
\text { educativo }\end{array}$ & $\begin{array}{l}\text { Clima familiar en las actividades de } \\
\text { aprendizaje, la participación de las familias en } \\
\text { el centro escolar, comunicación, expectativas. }\end{array}$ \\
\hline \multirow{2}{*}{$\begin{array}{l}\text { Dimensión } \\
\text { social }\end{array}$} & Factores contextuales & $\begin{array}{l}\text { Zona o barrio, redes de la sociedad civil, rural- } \\
\text { urbano, desempleo, presión social, Comunidad } \\
\text { Autónoma. }\end{array}$ \\
\hline & Grupo de iguales & $\begin{array}{l}\text { Amistades con bajo nivel educativo, } \\
\text { problemáticos, absentistas. Falta de relaciones } \\
\text { interpersonales, rechazo social. }\end{array}$ \\
\hline \multirow{2}{*}{$\begin{array}{l}\text { Dimensión del } \\
\text { sistema } \\
\text { educativo }\end{array}$} & $\begin{array}{l}\text { Factores de la } \\
\text { Administración } \\
\text { educativa }\end{array}$ & $\begin{array}{l}\text { Gasto público, ratio aula, rigidez del sistema } \\
\text { educativo, formación docente. }\end{array}$ \\
\hline & $\begin{array}{l}\text { Factores de los Centros } \\
\text { Educativos }\end{array}$ & $\begin{array}{l}\text { Titularidad, atención a la diversidad, } \\
\text { agrupamiento, metodologías, plan de } \\
\text { convivencia, método de evaluación, plan de } \\
\text { acción tutorial, coordinación familia-escuela. }\end{array}$ \\
\hline
\end{tabular}

Fuente: Elaboración propia

\subsection{Dimensión personal}

Dentro de esta dimensión se pueden distinguir dos subgrupos de factores. Por un lado, estarán los factores relacionados con aspectos biopsicosociales del individuo y, por otro, los aspectos que relacionan al individuo con el ámbito educativo.

Vivat Academia. Revista de Comunicación. 2021, nº 154, 25-52 


\subsubsection{Factores biopsicosociales del individuo}

La totalidad de autores analizados mencionan el género del alumno como un factor a tener en cuenta dentro del análisis del AETEn nuestro país, los varones tienen índices de abandono mayores que las féminas (Choi de Mendizabal y Calero, 2013; Rizo y Hernández, 2019; Rodríguez-Pineda y Zamora, 2021), concretamente un 8,4\% más alto (INE, 2020).

La mayoría de la bibliografía existente sobre la psicometría de la inteligencia encuentra correlaciones inversas entre la capacidad cognitiva del alumno y el AET, al igual que ocurre con las diferentes competencias del alumno (Hernández, 2019; Subirant, 2006). En un estudio realizado por Hernández-Prados y Alcaraz (2018) el peso de esta variable alcanza un nivel del $63,4 \%$. No obstante, si es cierto que la inteligencia del alumno tiene un peso importante en la continuidad de los estudios, no es menos cierto que la percepción que el alumno tenga sobre sus competencias y capacidad cognitiva también lo es (Constante-Amores et al., 2021). Los alumnos que se consideran intelectualmente incapaces de alcanzar el nivel exigido tienen mayor riesgo de abandono, por lo que la autoeficacia percibida se considera una influencia clave en la intención del abandono de la formación (Cerdá-Navarro, et al., 2020; Mena et al., 2010).

Varios aspectos relacionados con la personalidad del alumno constituyen variables de peso en su decisión de abandonar o continuar sus estudios en la formación reglada. Estudios como los de (Aramendi y Vega, 2013; Cerdá-Navarro, 2020; Mena et al., 2010, Rizo y Hernández, 2019, Subirant, 2006, entre otros) resaltan la relación entre aspectos como la autoestima, la motivación hacía el ámbito académico y el autoconcepto, con el AET. En referencia a esto, Martínez-Otero (2006) postula la importancia de la motivación de logro, relacionada con el nivel de aspiraciones del alumno en la toma de decisiones para la continuidad en el sistema educativo, puesto que esta variable tiene máxima influencia en la orientación del comportamiento hacía el éxito. Este mismo autor también afirma que la perseverancia mejora el rendimiento que es un factor protector contra el AET, sin embargo, la ansiedad se sitúa como un factor de influencia negativa en el aprovechamiento escolar aumentando el riesgo de abandono. También se incluyen dentro de esta dimensión variables referentes al estilo de aprendizaje (González-Pienda, 2003) y aspectos como la tolerancia a la frustración y la satisfacción inmediata (Alemany et al., 2013).

Otra de los factores que están relacionados tanto con el rendimiento escolar como con el abandono prematuro es el locus atribucional del alumno. Los sujetos que atribuyen su éxito escolar a factores internos y estables en el tiempo, (capacidad), y/o a factores internos no estables, (esfuerzo) producen en el sujeto unos sentimientos de autoconfianza, autoestima, de valoración positiva y de satisfacción que sirven como profiláctico con respecto al abandono escolar (Barca et al., 2000).

Vivat Academia. Revista de Comunicación. 2021, nº 154, 25-52 
Con respecto a los hábitos y estilos de vida de los alumnos hay estudios que demuestran que el rendimiento escolar puede verse afectado por el consumo de diferentes medios electrónicos de comunicación (televisión, videojuegos e internet), que forman parte de la actividad diaria de nuestros jóvenes en su socialización. De esta manera, se ha observado que el uso continuado de medios de comunicación electrónicos conlleva una menor dedicación al estudio, apreciándose una repercusión en el rendimiento académico y por lo tanto, aumentando el riesgo de AET (LópezBecerra, 2011; Sauquillo y Bellver, 2008). Esta problemática, conlleva a su vez la reducción de horas de sueño, lo que incide en un bajo rendimiento escolar debido a la alteración de ciertas funciones ejecutivas como son la concentración y la memorización (Davila, 2010), que unido al incremento del absentismo escolar forman un perfecto caldo de cultivo para el abandono de los estudios.

\subsubsection{Factores referentes a la relación individuo-ámbito educativo}

Unido a lo anterior se encuentra el absentismo escolar en secundaria, que desemboca con frecuencia en el AET, es uno de los factores más claramente asociados a consumos de sustancias adictivas (Navalón y Ruiz-Callado, 2012). Existe una clara relación entre el rendimiento académico del alumno y el AET (Constante-Amores, et al., 2021; Rizo y Hernández, 2019), por lo que la historia escolar de la persona es un factor a tener en cuenta en el análisis del constructo. Una de las investigaciones que lo corrobora es el realizado por Mena et al., (2010) donde se afirma que el alumnado que abandona tempranamente los estudios, presenta una desvinculación con la práctica educativa habitual y una baja participación en el aula en los primeros cursos de secundaria. Este alumnado deja de presentarse a las pruebas calificativas de muchas de las asignaturas, por lo tanto, una de las variables que mejor predice el AET es el absentismo a las pruebas de evaluación de las asignaturas. En la Formación Profesional de Grado Medio el abandono principalmente se produce por la no superación de un número significativos de asignaturas en el primer curso.

La falta de hábitos y técnicas de estudio del alumno tienen un gran poder predictivo del rendimiento académico, asociado en muchas ocasiones al posterior abandono, siendo la planificación del estudio en lo que se refiere a la organización y la confección de un horario realista, uno de los principales factores predictivos (Constante - Amores, 2021; Martínez-Otero, 2009). Unido a ello, otro de los aspectos que prevé el abandono escolar es la repetición de cursos escolares, tanto en primaria como en secundaria, de modo que el alumnado que ha repetido curso en alguna ocasión durante la educación obligatoria, tiene más probabilidades de abandonar el sistema educativo (Cerdánavarro, 2020; Choi y Mendizabal, 2013; Mena et al., 2010, entre otros). Tanto el absentismo como la falta de hábitos de estudio crean un desfase entre los conocimientos y nivel competencial del alumno y el del grupo de referencia que supone un factor determinante en el AET Si existe demasiado desfase curricular se produce en el alumno una gran desmotivación y sentimiento de falta de capacidad y frustración que puede tener incidencia en la intencionalidad del alumno a la hora de plantearse continuar con sus estudios (Camacho, 2018).

Vivat Academia. Revista de Comunicación. 2021, nº 154, 25-52 


\subsection{Dimensión del contexto familiar}

La familia se ha considerado como uno de los indicadores predictivos del AET, tanto en lo que respecta a los aspectos psicosociales, como en su implicación con el ámbito escolar.

\subsubsection{Factores psicosociales de la familia}

Diversos estudios muestran como la clase social y los niveles de estudio del padre y/o madre juegan un importante papel predictivo en el AET de los descendientes. En este sentido, los alumnos cuyos progenitores tienen estudios superiores están más protegidos en cuanto al riesgo de abandonar los estudios de forma prematura (Constante-Amores, 2021; Martínez-Otero, 2009; Rizo y Hernández, 2019). La escasez de recursos económicos de las familias puede frenar el proceso formativo de los hijos (Martínez-Otero, 2009). Un bajo nivel de ingresos familiares puede producir la imposibilidad de que el alumno acuda a actividades extraescolares, además puede dificultar la adquisición de cierto material escolar como libros de consulta $\mathrm{u}$ ordenadores (Mora, 2010). Unido a lo anterior, en las familiares con escasos recursos económicos, aumenta la necesidad de incorporación al mercado laboral lo antes posible de los hijos (Camacho, 2018; Hernández-Prados y Alcaraz, 2018; Subirant, 2006).

Otro de los factores que inciden en el AET es la posibilidad de empleabilidad en el entorno familiar con baja cualificación. El hecho de no tener la necesidad de tener una titulación para la incorporación al mercado laboral hace que la motivación por seguir los estudios descienda y por lo tanto aumente la intención de abandono (Camacho, 2018; Subirant, 2006).

A los aspectos citados anteriormente se debe añadir el país de origen de las familias, debido a que se ha comprobado un aumento del riesgo de abandono en familias extranjeras (Rizo y Hernández, 2019), especialmente cuando la lengua materna no es el español (González-Rodriguez et al., 2010).

La etria a la que pertenece el alumno constituye uno de los factores predictivos. En España ser gitano supone un riesgo añadido en la deserción escolar (Choi de Mendizabal y Calero, 2013). Estos mismos autores también afirman que la desestructuración familiar constituye uno de los factores de incidencia, especialmente en ambientes agresivos o familias en riesgo de exclusión social (Choi de Mendizabal y Calero, 2013; Mena et al., 2010).

\subsubsection{Factores referentes a la relación familia-ámbito-educativo}

Además de las características socio-demográficas de la familias, el clima familiar, al respecto del ámbito escolar de los hijos, tiene una importante fundamental en que los descendientes continúen sus estudios tras finalizar la educación obligatoria. La apreciación de los padres en referencia a la utilidad de la formación va a afectar en la percepción de los hijos sobre este hecho, lo que disminuye la intención de abandono

Vivat Academia. Revista de Comunicación. 2021, nº 154, 25-52 
(Camacho, 2018). Cuando las familias hablan frecuentemente con sus hijos sobre la escuela contribuyen a mejorar la implicación de éstos en las tareas escolares y aumentar la percepción de utilidad de la formación (Cerdá et al., 2020; Alemany et al., 2013). Unido a ello se encuentran aspectos como supervisión en realización de las actividades de aprendizaje en el hogar. Pérez-Díaz, et al., (2009) constatan la existencia de una asociación directa entre el número de asignaturas suspensas y la frecuencia parental de ayuda en las tareas escolares, mostrando que, a mayor implicación menor número de suspensos y por lo tanto, menos riesgo de abandono futuro, puesto que como hemos apuntado anteriormente, una historia escolar poco exitosa o con repeticiones de cursos incide en la deserción de la formación (Camacho, 2018).

La comunicación familia-centro es otro de los factores que encontramos en la bibliografía como potenciales predictores del AET. Aquellas familias que hablan frecuentemente con el equipo docente de sus hijos, bien sea de forma presencial o a través de medios telemáticos, reducen la intención de abandono de la formación de sus hijos (Hernández-Prados y Álvarez, 2006). Esta misma tendencia se produce con la utilización de las aplicaciones de los centros, las redes sociales y los recursos comunitarios (Camacho, 2018).

Hay que destacar como factor protector contra el abandono, las expectativas que tienen los padres con respecto a la capacidad de sus hijos, de modo que si las expectativas son realistas aumentan la autoestima del alumno y la sensación de estar capacitado para poder continuar con la formación reglada (González-Rodríguez, 2016; Martínez-Otero, 2009).

\subsection{Dimensión social}

Además de la familia, que actúa como agente socializador y educativo y que al tener un peso especial dentro de las decisiones y comportamiento de los hijos la hemos considerado una dimensión propia, existe otros aspectos sociales que también influyen en la intencionalidad de los alumnos en la continuación de los estudios. Esta dimensión está constituida por dos factores: Por un lado, estarán los aspectos relacionados con factores contextuales en cuanto al lugar de residencia y, por otro lado, los aspectos relacionados con el grupo de iguales.

\subsubsection{Factores contextuales}

Vivir en una zona o barrio marginal o en una zona deprimida como pueblos muy pequeños en área rural inciden negativamente en que el alumnado abandone prematuramente los estudios (Camacho, 2018; Mena et al., 2010). Dentro de la zonificación encontramos asociados factores relacionados con las redes de la sociedad civil como las asociaciones, equipamientos culturales y espacios de ocio que inciden positivamente en la culturización de los residentes y a su vez en el descenso de la tasa de abandono (Subirant, 2006). A su vez, relacionado con el nivel socio-cultural de la zona, se sitúa la influencia que ejerce la sociedad para que el individuo continúe con los estudios, de modo que en contextos más cultos se percibe una presión social para

Vivat Academia. Revista de Comunicación. 2021, nº 154, 25-52 
continuar en la formación reglada y obtener un título post-obligatorio (HernándezGarcía, 2011).

Dentro del conjunto de variables que describen las características del entorno, las estimaciones muestran un efecto positivo entre residir en una zona con una tasa de desempleo juvenil superior a la media nacional y la probabilidad de continuar los estudios. Este hecho puede ser interpretada por el menor coste de oportunidad que comporta su decisión de prolongar su vida académica, entendiéndose pues el mayor desempleo juvenil como un incentivo para la permanencia en el sistema educativo de los individuos (Casquero y Navarro, 2010; Subirant, 2006).

\subsubsection{Grupo de iguales}

Amistades de bajo nivel académico, grupo de amigos problemáticos que dificultan el progreso escolar, compañías con alto nivel de absentismo, habitualmente ejercen una gran influencia en la edad adolescente para asumir el mismo comportamiento e incrementar el riesgo de abandono (Sánchez-Alhambra, 2016). En un estudio cualitativo realizado por Mena et al. (2010), con una muestra de alumnos que ya han abandonado la formación, se determina que la clave es la presión para no destacar, intentar no ser distintos del resto del grupo, por lo que las expectativas personales se ajustan a lo mayoritario en el ámbito de relaciones de cada alumno.

Por otro lado, la falta de relaciones interpersonales y mala relación con el grupo-aula inciden directamente en el abandono (Sánchez-Alhambra, 2016). El sentimiento de rechazado social, no tener buenas habilidades sociales o una baja participación, aumentan el absentismo escolar y el posterior abandono definitivo de las aulas (Ekstrand, 2015; Esch et al., 2014). Sin embargo, una buena relación con los compañeros puede ejercer un efecto motivador para asistir a la escuela y aumentar la vinculación del alumnado con el aprendizaje y la formación, sirviendo de profiláctico para el abandono (Cerdá-Navarro et al., 2021).

\subsection{Dimensión del sistema educativo}

Dentro de esta dimensión se encuentran dos grupos de factores: las administraciones educativas superiores, es decir, los organismos a nivel estatal y autonómico y, los factores relacionados con el centro educativo.

\subsubsection{Factores de la Administración educativa}

Dentro de este factor el gasto público en educación es uno de los aspectos más estudiados a la hora de explicar el rendimiento del sistema educativo, ya que evidencia el esfuerzo inversor que los gobiernos ejercen en educación. Sin embargo, en la literatura existe una notable divergencia de resultados e interpretaciones. En este sentido, son numerosos los estudios que concluyen que las variables referidas al gasto público en educación no son determinantes a la hora de explicar ni los resultados educativos ni la tasa de AET (Marchesi, 2003; Calero et al., 2010). A este respecto, 
Hanushek (2006) destaca el enfoque erróneo que plantean distintos gobiernos, que toman como base para sus políticas educativas un enfoque cuantitativo, en el que ignoran otras variables, como los incentivos o la estructura institucional del sistema educativo. Sin embargo, en contraposición con esta afirmación, el estudio de Holmlund et al. (2010) muestra que el incremento de gasto en educación por alumno aumenta significativamente los resultados de los tests de competencias del alumnado. En nuestro país, el estudio realizado por Pérez-Esparrells y Morales (2012) revela que el nivel de gasto educativo en educación secundaria mantiene una relación negativa con resultados educativos como el porcentaje de individuos que no consigue titularse en Educación Secundaria Obligatoria (ESO).

Otro de las variables más controvertidos, puesto que tampoco existe acuerdo entre los investigadores, es la ratio de las aulas. Estudios como el de Calero et al. (2010) no detectan una relación significativa entre las ratios que representan el tamaño del aula y los resultados educativos en general. Por el contrario, otros estudios muestran que la existencia de aulas más reducidas tiene efectos beneficiosos sobre los resultados educativos (Krueger y Whitmore, 2001; Finn et al., 2005), señalando que la reducción del aula es un aspecto fundamental para garantizar la reducción del fracaso y el AET, especialmente en el caso de contextos educativos con alumnado de bajo rendimiento (Dale, 2010).

Un aspecto a tener en cuenta es la rigidez del sistema educativo. La UNESCO (2012) publicó un informe donde se concluía esta rigidez curricular como uno de los principales problemas de la educación y, es que los sistemas educativos en secundaria parecen estar diseñados más para excluir que para incluir (Benchimol, et al., 2011; Recio y De la Cruz, 2011). Según Pérez-Gómez (2012), una de las características de las escuelas actuales es la transmisión de un conocimiento academicista que no se adapta a las necesidades de la sociedad actual ni favorece el desarrollo personal de los futuros ciudadanos, lo que incide en la desmotivación del alumnado y aumenta el riesgo de abandono. Martín y Luna (2016) señalan la existencia de planes de aprendizaje personalizados y flexibles como uno de los pilares que evitarían el AET.

Dentro de esta dimensión encontramos la formación docente, en lo que se refiere a la formación inicial y la continua. En este sentido se debe tener en cuenta que los países que poseen menores cifras de AET, implementan importantes innovaciones en los modelos de formación inicial y permanente, además en la que atañe a los primeros años de la vida profesional, etapa muy importante en el proceso de enseñar a aprender (Vaillant y Marcelo, 2015). Países como Inglaterra, Irlanda del Norte, Escocia, Francia, Suiza, Israel, Australia, Nueva Zelanda, Japón y Estados Unidos, todos ellos con unos índices de abandono más bajos que nuestro país, han puesto en marcha diversos programas de inserción para el profesorado novel.

\subsubsection{Factores de los centros educativos}

Los centros educativos constituyen el segundo nivel de concreción donde se contextualiza el curriculum. Por ello, es competencia del centro, la elaborando del

Vivat Academia. Revista de Comunicación. 2021, nº 154, 25-52 
Proyecto Curricular de Centro (PCC) dentro del Proyecto Educativo de Centro (PEC). Los elementos esenciales que han de surgir de este segundo nivel de concreción son: objetivos generales, secuenciación de contenidos, estrategias metodológicas, organización del espacio y del tiempo y, determinar los recursos y criterios generales de evaluación.

Existe también un amplio debate sobre la incidencia de la titularidad del centro educativo en los resultados educativos. En este sentido, diversas investigaciones han señalado que los centros educativos de titularidad privada, tanto aquellos que tienen un concierto como los privados no concertados, presentan unos resultados notablemente mejores que los públicos en el estudio PISA (West y Woessmann, 2010; Alegre y Subirats, 2013). Sin embargo, otros estudios revelan que este efecto pierde su significatividad cuando se controlan las variables que tienen que ver con el estatus socioeconómico y cultural del alumnado (Calero y Escardíbul, 2007; Mancebón et al., 2012). El peso que el centro educativo tiene con respecto al AET, con independencia de la titularidad, se materializa en diferentes variables. Montes y Parcerisa (2016) subraya que la atención a la diversidad, el tipo de agrupamientos del alumnado y los mecanismos disciplinarios incluidos en el plan de convivencia empleados con alumnos con problemas conductuales, comporta la pérdida de expectativas sobre el futuro académico y propicia el desenganche educativo aumentando el riesgo de abandono. En este sentido, la metodología es un elemento compensador del AET, siendo más motivantes para el alumnado las metodologías activas, los métodos más creativos y las clases prácticas y participativas, mientras que la metodología más tradicional les resulta más ardua y como consecuencia produce el alejamiento del alumnado de las aulas (Holgueras, 2016).

Unos de los aspectos que más claramente influyen en el AET son los criterios de evaluación y promoción. La organización Montessori Canela Internacional, presenta los resultados de su estudio sobre los efectos del sistema de evaluación por notas numéricas donde se pone de manifiesto que un $90 \%$ del personal educativo encuestado relaciona el AET con un sistema de evaluación demasiado estricto. Del informe se extrae que el sistema de evaluación actual tiene consecuencias negativas sobre los alumnos, generando la falsa idea de que lo importante es aprobar y no aprender, además de crear estrés y desmotivación entre el alumnado (Ecoaula, 2021).

Un aspecto incluido en las recomendaciones relacionadas con la reducción del AET es el desarrollo de un buen plan de acción tutorial, en la que se incluye la orientación y el seguimiento individualizado del alumnado (Carrasco, et al., 2015). El papel del profesorado y de órganos como el departamento de orientación del centro son claves para el alumnado en riesgo de abandono escolar fomentando su integración en el centro y facilitando que pueda reconciliarse con sus capacidades (Clemente, 2010).

Otro variable dentro de la dimensión que estamos tratando es la cooperación entre las familias y el centro educativo. Las experiencias cooperativas son altamente positivas para prevenir el AET, incidiendo en el rendimiento académico, en la autoestima del alumno, en la reducción del absentismo y mejora los hábitos de estudio (Álvarez, 2012; Moreno,

Vivat Academia. Revista de Comunicación. 2021, nº 154, 25-52 
2010), todos ellos, como hemos visto en párrafos anteriores, variables implicadas en la prevención del riesgo de AET.

Como hemos podido observar a lo largo de este apartado, nos encontramos ante un fenómeno complejo en el que intervienen factores personales, familiares, sociales, políticas, económicas y educativos. Precisamente por ello es de suma importancia detectar los aspectos que influyen en el abandono con objeto de que los agentes socioeducativos puedan identificar de forma prematura al alumnado de riesgo potencial e intervenir lo antes posible para solventar este hecho con el objeto de desarrollar acciones compensatorias destinadas a desarrollar una educación equitativa.

A continuación, se muestra un planteamiento de análisis integral con objeto de analizar los factores determinantes del AET.

\section{METODOLOGÍA}

Como anteriormente se ha mencionado, el trabajo presentado en este documento constituye la primera parte de un estudio más amplio, en el que, a partir del método de análisis de los factores determinantes del AET que presentamos a continuación, se desarrolla un cuestionario ad hoc donde se integran las dimensiones expuestas. Dicho instrumento de recogida de datos se aplicará al alumnado de $4^{\circ}$ de ESO, tanto en la modalidad académica como en la de aplicadas, alumnado de Programas de Mejora del Aprendizaje y el Rendimiento 2 (PMAR2), Formación Profesional Básica (FPB), $1^{\circ}$ de Ciclo Formato de Grado Medio, aulas terapéutico-educativas y aulas de inserción socio-educativas.

El primer paso se trató de la realización de una exhaustiva revisión bibliográfica de diferentes investigaciones en relación al AET, a través de 10 bases de datos: Dialnet, Scopus, ERIC, Education Data base, Web of Science, TESEO, GRAÓ e-premium, Ejournal y Google académica. Todas y cada una de ellas nos permiten el acceso a las diferentes fuentes documentales en inglés y en castellano: artículos de revista, capítulos de libros, actas de congresos, tesis doctorales, monografía, etc. Para la realización de la búsqueda bibliográfica se ha utilizado prioritariamente la plataforma de la Universidad de la Rioja y Google Scholar. Tras la selección, se procedió a organizar las referencias a través del gestor bibliográfico Mendeley permitiendo eliminar las referencias duplicadas. Finalmente, el resultado de nuestra selección utilizando el criterio de afinidad de los títulos de las referencias con nuestro tema objeto de estudio ha sido de 89 .

Las preguntas de investigación de las que se parte son: ¿Qué motivos llevan a los alumnos a abandonar los estudios antes de la obtención de una titulación oficial posterior a la secundaria? ¿Cuáles son las dimensiones que posibilitan explicar el AET? Esta inquietud se concreta en un objetivo general que sería: crear un modelo de análisis eficaz y contrastado que sirva como herramienta para determinar los factores de riesgo y posibilitar el diseño estrategias de intervención para aquel alumnado que se determine como potencialmente de riesgo.

Vivat Academia. Revista de Comunicación. 2021, nº 154, 25-52 


\section{RESULTADO}

Nuestra propuesta de modelo de investigación para el análisis de las dimensiones que influyen en la intención de AET se ancla en dos premisas fundamentales.

Por un lado, el análisis de la literatura sobre los factores de incidencia en la intención de AET muestra la influencia de variables de diferente naturaleza que se pueden categorizar en 4 dimensiones (ver figura 2).

Por otro lado, se ha realizado un recorrido por diferentes modelos explicativos de la conducta humana desde diferentes líneas teóricas como son:

- Modelos con perspectiva actitudinal, en las que el peso de la realización de una conducta recae sobre las actitudes del individuo.

- Teorías de la motivación humana como principal aspecto que determina la conducta.

- Modelos vinculados a aspectos sociales.

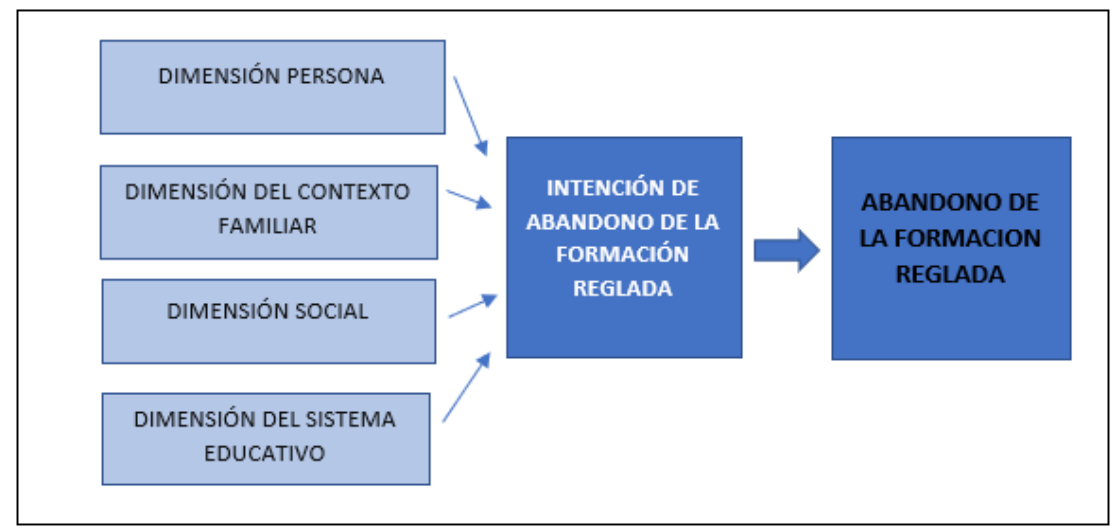

Figura 2. Dimensiones de influencia en el Abandono Escolar Temprano Fuente: Elaboración propia

Tras el análisis de dichos modelos se determina que el modelo UTAUT (Venkatest et al., 2003) (ver figura 2) ha sido ampliamente empleado como teoría explicativa de la intencionalidad orientada hacía una determinada acción, es decir, como un contrastado modelo que posibilita la explicación de ciertas conductas y comportamientos humanos. Siendo conscientes de que la prevalencia de estudios que emplean este modelo están centrados en reconocer los factores que explican en mayor medida el comportamiento de las personas frente a la tecnología, algunos autores parecen probar la validez del modelo en el marco concreto de la acción educativa (Bing, 2013; Oye, et al., 2014; Raza, et al., 2020; Salloun y Shaalan, 2019). Sobre la base de estos resultados, nuestra propuesta de análisis versa sobre las dimensiones subyacentes que se encuentran en la trastienda de la intencionalidad del alumnado para abandonar tempranamente el sistema educativo. 
Análisis de los factores predictivos del abandono escolar temprano.

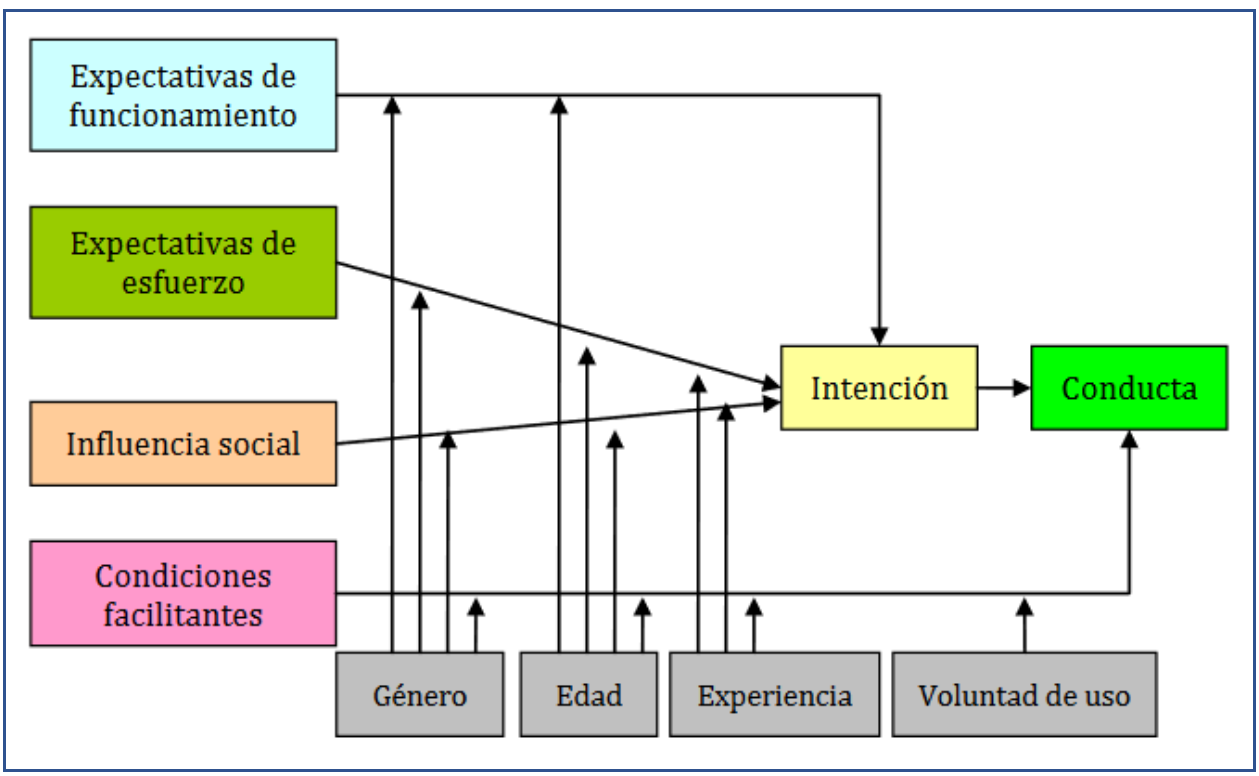

Figura 3. Esquema de la Teoría Unificada de Aceptación y Uso de la Tecnología Fuente: Elaboración propia a partir de Venkatesh et al., 2003

Nuestro planteamiento se enmarca en el grupo de estudios que extienden y adaptan el modelo UTAUT con el fin de analizar intencionalidades diversas. El modelo propuesto toma como referencia las dimensiones base de la UTAUT realizando una adaptación de las mismas a partir de la literatura relacionada con el problema objeto de estudio.

\subsection{Dimensión. Expectativas de Funcionamiento}

En sintonía con el modelo propuesto por Ventakesh (2000), esta dimensión hace referencia al valor de la tarea y la expectativa de que el éxito de la misma está bajo su control, aspecto condicionado a su vez por la autoeficacia percibida. En caso del AET, los juicios de valor del alumno sobre sí mismo y sobre la tarea, se posicionan como principales agentes para la consecución del objetivo último, en definitiva, la obtención de algún título oficial posterior a la obligatoriedad.

Esta dimensión recoge de forma mayoritaria la dimensión personal, tanto los factores biopsicosociales del individuo, como la relación de éste con el ámbito educativo, analizados en el epígrafe 2. Está constituida por los siguientes factores:

\subsubsection{Utilidad percibida}

En nuestro campo de estudio estaríamos hablando de la percepción que tiene un alumno sobre la rentabilidad de los títulos oficiales posteriores a la Educación Secundaria Obligatoria. En qué grado considera dicho alumno que la obtención de una titulación a través del sistema reglado le va a proporcionar mejoras en aspectos personales, prosperidad social, o la obtención de un empleo de calidad. En definitiva, la apreciación del alumno sobre si la obtención de titulación le va a aportar una mejora

Vivat Academia. Revista de Comunicación. 2021, nº 154, 25-52 
personal y una evolución sociolaboral, en comparación con la no-obtención de la misma.

Algunas de las variables que analiza este factor son las expectativas de utilidad de la formación y la cultura, la valoración de los títulos oficiales (Mena, et al., 2010) y los requisitos de acceso al mercado laboral (Alemany, et al., 2013), entre otros.

\subsubsection{Autoeficacia percibida}

Se trata de un factor que recae de forma prioritaria sobre las ideas del alumno y que consiste en la esperanza o posibilidad percibida que tiene el individuo de obtener una titulación oficial superior a los estudios obligatorios.

Dentro de este factor se analizarán variables como la percepción de tiene el alumno sobre su capacidad cognitiva, su competencia organizativa, su tolerancia a la frustración, su capacidad de perseverancia, su autoestima y autoconcepto, entre otras (González-Pienda, 2003; González-Rodríguez, et al., 2016; Hernández-Prados y Alcaraz, 2018).

\subsection{Dimensión. Expectativas de esfuerzo}

En el contexto relacionado con el AET, esta dimensión quedaría cotejada como la percepción que tiene el alumno sobre el grado de esfuerzo que debe realizar para la consecución de un título oficial en los años posteriores a la obtención del título de ESO.

Esta dimensión estaría vinculada tanto con la dimensión referente al sistema educativo como con la dimensión personal, analizados en el epígrafe 2. Se descompone en dos factores:

\subsubsection{Facilidad de uso global}

En el caso del AET este factor quedaría definida como la apreciación en cuanto a la magnitud e intensidad de esfuerzo que el alumno debe realizar, para la obtención de una titulación post obligatoria a través del sistema educativo reglado. En definitiva, es la percepción que presenta el alumno sobre cuánto esfuerzo tiene que efectuar para conseguir dicho título. El grado de facilidad-dificultad que percibe en la utilización exitosa de la formación reglada.

Este factor es independiente a la percepción que tenga el alumno sobre la utilidad y ventajas que la pueda aportar la obtención de un título. Se trata de una percepción global sobre la dificultad de la consecución de este, independiente del factor utilidad percibida (ver punto 4.1.1). 


\subsubsection{Facilidad de uso relativo}

Este factor está íntimamente relacionado con la anterior en cuanto que mide la percepción del alumno sobre el esfuerzo a realizar, sin embargo, dista del factor facilidad de uso global en que el esfuerzo apreciado es relativo a la percepción que tiene el alumno sobre las ventajas, posibilidades y mejoras personales y sociolaborales que la obtención de un título postobligatorio le va a aportar. En definitiva, la percepción del esfuerzo está mediatizado por la apreciación que presenta del factor utilidad percibida.

\subsection{Dimensión. Influencia social-educativa}

En nuestro campo, esta dimensión alude al grado en que las personas y grupos influyentes para el individuo consideran que éste debería continuar la educación posterior a la obligatoriedad a través del sistema escolar reglado. En la casuística que nos ocupa hablaríamos de influencia socio-educativa por el potencial influjo de los agentes educativos. A su vez, algunos factores contextuales están relacionados con aspectos educativos, como pueden ser, el nivel formativo de la familia y la historia escolar del grupo de iguales.

Esta dimensión está directamente relacionada con la dimensión contexto familiar y la dimensión social analizadas en el epígrafe 2. Está compuesta por dos factores:

\subsubsection{Norma subjetiva}

Esta variable es definida de un modo global como la percepción de un individuo acerca de si las personas importantes para ella aprueban o desaprueban su conducta (Taylor y Todd, 1995; Chen y Dhillon, 2003). Representa la influencia que ejerce la sociedad en general, y las personas que el individuo considera importantes para él en particular, a la hora de condicionar su comportamiento. Este influjo se encuentra generalmente ponderado por el peso que el individuo atribuye a cada persona o grupo social (Hernández-García, 2011).

Delimitándolo a nuestro campo, supondría el grado de influencia que, la sociedad en general y las personas o grupos significativos para el alumno en particular, tendría para que éste continúe o abandone los estudios. En definitiva, en tanto en cuanto, el influjo de las normas sociales y la opinión de los sujetos apreciados como valiosos para el alumno, van a mediatizar la intención de este sobre el abandono de los estudios reglados posteriores a la obligatoriedad.

Dentro de esta variable se encuentran aspectos como apoyo y clima de la familia en temas relacionados con los estudios (Sánchez-Alhambra, 2017), percepción del grupo de iguales y nivel educativo de los mismos (Choi de Mendizabal y Calero, 2013), percepción de prestigio social con la obtención de titulación, imagen social de la educación (Hernández-Prados y Alcaraz, 2018), expectativas del profesorado (Alemany, et al., 2013), entre otros aspectos.

Vivat Academia. Revista de Comunicación. 2021, nº 154, 25-52 


\subsubsection{Factor contextual}

El contexto se define como el conjunto de circunstancias que rodean una situación y sin las cuales no se puede comprender correctamente. En el constructo del abandono escolar objeto de estudio, las variables contextuales quedarían definidas como el ambiente, físico o simbólico, en el que el alumno se ha desarrollado y/o se encuentra en el momento de la toma de decisión. Se refieren a un conjunto de fenómenos, situaciones y circunstancias, no comparables a otras, que rodean o condicionan la intencionalidad de continuar con los estudios reglados, o por el contrario abandonar de forma temprana la escolarización.

Algunas de éstas serían el nivel socio-educativo y el clima educativo de la familia (Choi y Mendizabal, 2016; Rizo y Hernández, 2019), características propias de la comunidad a la que pertenece (Bienes, 2019), barrio o zona de residencia (Mena et al., 2010), composición y tipología familiar (González-Pienda, 2003; Subirant, 2006) y posibilidades de incorporación al mercado laboral (Hernández-Prados y Alcaraz, 2018; Subirant, 2006), entre otros.

\subsection{Dimensión. Condiciones facilitadoras}

Esta dimensión se puede definir como el grado en el que el individuo cree que existe una infraestructura técnica y organizativa que da soporte al sistema (LópezHernández y Silva, 2016).

En el caso del abandono escolar esta dimensión estaría relacionada de forma prioritaria con factores educativos analizados en el capítulo 3 y se descompone en tres:

\subsubsection{Recursos funcionales}

Dentro de este factor estarían enmarcados las variables que señalan las pautas y regulan las actuaciones educativas, aquellas que proporcionan el marco idóneo de trabajo como: Los órganos colegiados y órganos de gobierno, el clima, los horarios, el sistema y método de evaluación, propuesta de actividades extraescolares, coordinación con instancias externas, servicios complementarios y planificación, entre otros. (Alemany et al., 2013; Camacho, 2018; Choi de Mendizabal y Calero, 2013; Constance-Amores et al., 2021; González-Pienda, 2003; Hernández-Prados y Alcaraz, 2018; Marchesi, 2006; Mena, et al., 2010; Rizo y Hernández, 2019; Sánchez-Alhambra, 2017 y Subirant, 2006).

\subsubsection{Recursos materiales}

Dentro de este factor se encuentran los elementos materiales a los que se refiere la estructura de los componentes presentes en la organización educativa. Son los soportes básicos sobre los que se cimientan los demás, dentro de los que encontramos esencialmente, el espacio, los recursos mobiliarios y el material de uso didáctico. (Choi

Vivat Academia. Revista de Comunicación. 2021, nº 154, 25-52 
de Mendizabal y Calero, 2013; González-Pienda, 2003; Hernández-Prados y Alcaraz, 2018; Rizo y Hernández, 2019; Sánchez-Alhambra, 2017).

\subsubsection{Recursos humanos}

Integrados en este factor se hallan los elementos personales a los que se refiere la disposición de los actores presentes en la organización educativa, en definitiva, al capital humano que posé el sistema escolar. De forma principal estaría formado por el alumnado, el profesorado, el equipo directivo, equipos de orientación, otros agentes educativos, familias y personal de administración y servicios (Alemany et al., 2013; Choi de Mendizabal y Calero, 2013; González-Pienda, 2003; González-Rodríguez, et al., 2016; Hernández-Prados y Alcaraz, 2018; Mena, et al, 2010; Rizo y Hernández, 2019; Sánchez-Alhambra, 2017 y Subirant, 2006).

\subsection{Aspectos moderadores}

Ventaketh et al., (2003) establecen 4 factores moderadores dentro del modelo UTAUT, como son el género, la edad, la experiencia previa que presenta el individuo en cuanto a la utilización de sistemas similares y la voluntad de uso en referencia a si el empleo del sistema es voluntario o impuesto. (Michel, et al., 2012). Reproduciendo dicha estructura, partiendo del estudio de las dimensiones que influyen en el AET, (epígrafe 2) en nuestro modelo de análisis proponemos los siguientes factores moderadores:

\subsubsection{Identidad}

Dentro de este factor se incluyen variables relacionados con aspectos demográficos del alumno, en referencia al género, la edad, capacidad cognitiva real, lenguaje materno y etnia, entre otros. (Choi de Mendizabal y Calero, 2013; Constance-Amores et al., 2021; González-Pienda, 2003; Hernández-Prados y Alcaraz, 2018; Mena, et al., 2010; Rizo y Hernández, 2019; Sánchez-Alhambra, 2017; Subirant, 2006).

\subsubsection{Historia escolar}

El análisis de la literatura sobre los componentes de influencia del abandono escolar nos indica que la historia académica del alumno interviene de forma directa en la renuncia de la formación reglada hacía la obtención de una titulación oficial. Dentro de este factor nos encontramos variables como la repetición de cursos escolares, necesidad de apoyo educativo, itinerario de escolarización, expulsiones del centro por actitudes disruptivas, desfase entre el nivel competencial del alumno con respecto al grupo, absentismo escolar, etc. (Camacho, 2018; Choi de Mendizabal y Calero, 2013; Consejería de Educación de Castilla León, 2015; González-Pienda, 2003; GonzálezRodríguez, et al., 2016; Rizo y Hernández,2019; Sánchez-Alhambra, 2017).

Vivat Academia. Revista de Comunicación. 2021, nº 154, 25-52 


\subsubsection{Rasgos personales}

Son varios los autores que aseguran la influencia de los aspectos emocionales del alumno en la decisión de abandonar prematuramente los estudios. Según la clasificación expuesta por Gladys, (2002) los rasgos personales potencialmente influyentes se pueden agrupar en dos: Por un lado, estaría los relacionados con aspectos emocionales como los desórdenes de interiorización, entre los que nos encontramos variables como; el sobrecontrol, ansiedad, retraimiento, timidez, depresión, el miedo o el sentimiento de ridículo. Por otro lado, encontramos desórdenes de exteriorización, es decir, los hábitos del alumno en los que se incluyen variables como; el infracontrol, la desobediencia y el consumo de sustancias adictivas, etc. (Alemany, et Al., 2013; Cerdá, Sureda y Salvá, 2020; González-Rodríguez, et al., 2016; Rizo y Hernández, 2019).

La siguiente figura esquematiza nuestro planteamiento integrador para el análisis de los factores determinantes del AET.

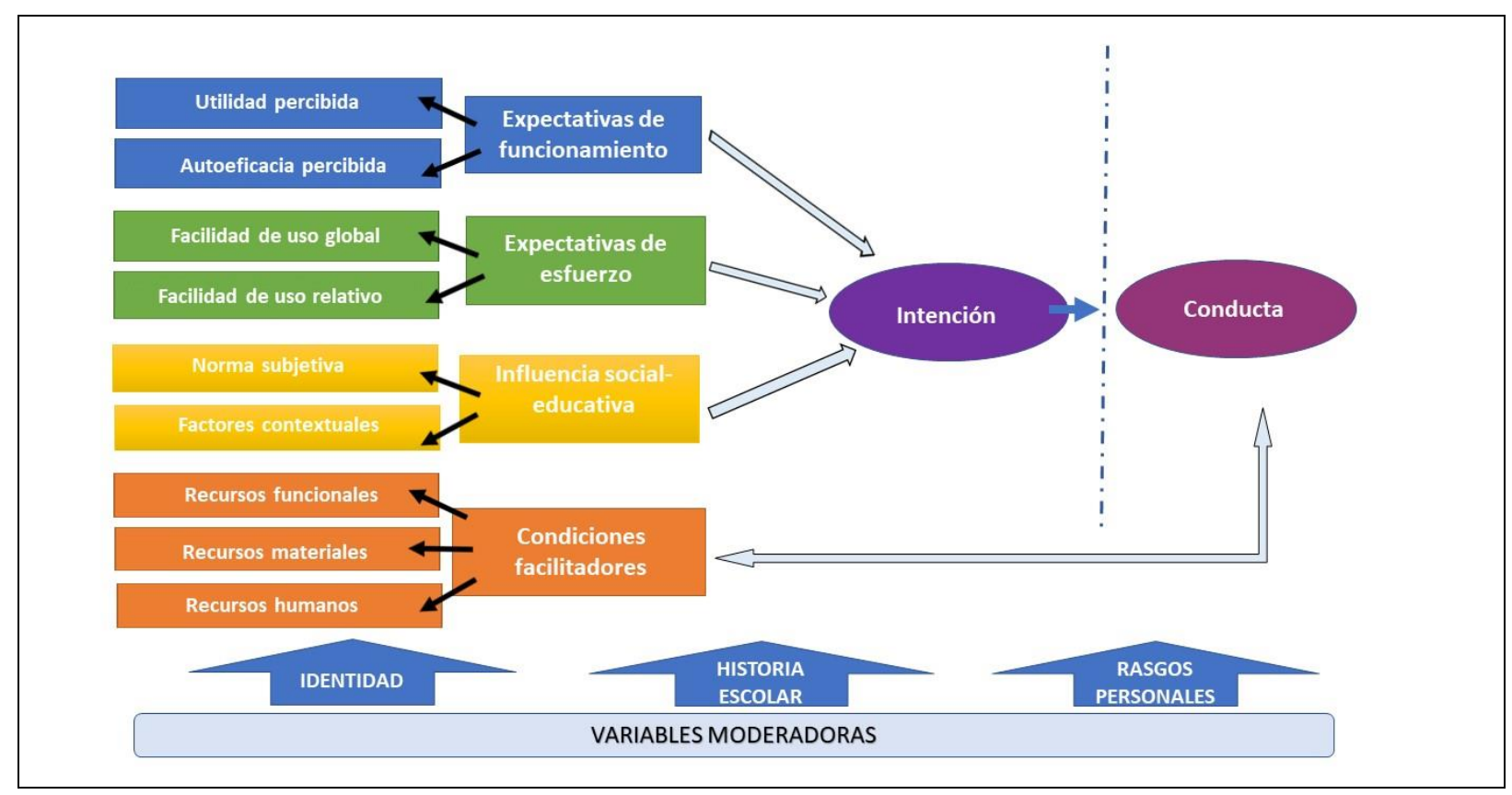

Figura 4. Adaptación del modelo UTAUT para el análisis de las dimensiones del AET Fuente: Elaboración propia

\section{DISCUSIÓN}

El presente estudio supone la primera parte de una investigación más amplia en la que, a través de un cuestionario ad-hoc desarrollado a partir del modelo de análisis de los factores determinantes del abandono prematuro expuesto en este estudio, se extraen datos para su posterior análisis. 
Desde nuestra pretensión de desarrollar un modelo integrador de análisis de la globalidad de factores de incidencia en el AET, se ha realizado una exhaustiva revisión bibliográfica categorizando los diferentes aspectos en cuatro grandes dimensiones. La primera de ellas sería la dimensión personal (Choi de Mendizabal y Calero, 2013; Rizo y Hernández, 2019; Rodríguez-Pineda y Zamora, 2021), en la que se encuentran los factores referentes a los aspectos biopsicosociales del individuo, como la motivación, el autoconcepto, la tolerancia a la frustración, la ansiedad y/o los estilos de aprendizaje. Dentro de esta dimensión, las diferentes investigaciones hacen referencia a factores relativos al individuo y su relación con los aspectos académicos, como la historia escolar, el desfase curricular y/o el absentismo (Cerdá-Navarro, 2020; Constante-Amores, 2021; Martínez-Otero, 2009).

El segundo contexto de análisis se refiere a la dimensión familiar, que a su vez, estaría dividida en los factores psicosociales de la misma, donde se integran aspectos como el nivel educativo de la familia o los recursos económicos de esta (Camacho, 2018; Hernández-Prados y Alcaraz, 2018; Subirant, 2006). Otro aspecto dentro de esta dimensión es la relación que establece la familia con el ámbito educativo, con factores como la supervisión en la realización de las actividades de aprendizaje de los hijos y/o la participación en el centro escolar (Alemany et al., 2013; Cerdá et al., 2020; GonzálezRodríguez, 2018).

La tercera de ellas sería la dimensión social, en la que se analizan los factores contextuales del entorno del alumno, en cuanto a características, recursos y posibilidades (Casquero y Navarro, 2010; Hernández-García, 2011; Mena et al., 2010) a lo que se le añade la influencia del grupo de iguales, los hábitos grupales y la formación académica de estos (Esch, etel., 2015; Sánchez-Alhambra, 2016).

Por último, estaría la dimensión del sistema educativo, vinculada a los factores propios de la administración educativa como pueden ser el gasto público destinado a educación o la ratio en las aulas (Calero, et al., 2010; Dale, 2010; Pérez-Esparrells y Morales, 2012), junto con los factores propios de los centros educativos como la titularidad, la atención a la diversidad o el tipo de agrupamiento del alumnado (Calero y Escardíbul, 2007; Mancebón et al., 2012; Montes y Parcerisa, 2016).

Si es cierto que las dimensiones anteriores son el punto de partida del análisis de los factores que inciden en el AET, no debemos perder de vista que el abandono del sistema educativo es una conducta personal, precedida en la mayoría de los casos, por una intencionalidad. Desde esta perspectiva, se ha realizado un recorrido de los diferentes modelos explicativos de la conducta determinando que el modelo UTAUT puede constituir una buena base para realizar una adaptación del mismo con el objeto de adecuarlo al análisis de los factores que se encuentran en la trastienda de la intencionalidad del alumnado para abandonar tempranamente los estudios.

El resultado de aunar las cuatro dimensiones de influencia en el AET con el modelo de análisis de la conducta UTAUT ha desembocado en un modelo de análisis global e integrador que recoge todos los aspectos implicados en el AET, junto con las variables moderadoras de los mismo.

Vivat Academia. Revista de Comunicación. 2021, nº 154, 25-52 


\section{CONCLUSIONES}

Tal y como se ha ido exponiendo a lo largo del presente texto, el nivel educativo de la población es un factor de alta incidencia en el desarrollo económico y social de las diferentes sociedades, tal y como se expone en la Estrategia Europa 2020, por lo que el AET va en detrimento del crecimiento de un país.

Siendo conscientes de la elevada tasa de AET de España, hemos desarrollado un modelo integrador en el que se aúnan las diferentes dimensiones, factores y variables incluidas en las mismas, potencialmente predictivas en la toma de decisión de un alumno en cuanto al abandono del sistema reglado para la consecución de un título posterior a la obligatoriedad. El tener un modelo de análisis de los factores determinantes completo e integrador que auné, por un lado, las principales dimensiones que los estudiosos consideran como variables de riesgo potencial para que el alumnado abandone los estudios de forma prematura y, por otro lado, que esté basado en un modelo de análisis de la conducta humana altamente contrastado, supone una importante herramienta de anclaje para agentes educativos e investigadores del tema.

Este modelo pretende ser, por un lado, el germen de futuras investigaciones que, partiendo de dicho modelo, desemboque en la creación de herramientas de recogida de datos como entrevistas guiadas, cuestionarios o encuestas, que faciliten la detección del alumnado de riesgo de abandono. Esto va a posibilitar desarrollar actuaciones preventivas de forma personalizada.

Por otro lado, pretende instruir al profesorado y a las instituciones educativas sobre los aspectos subyacentes del AET con el objetivo de que dicha problemática pueda ser abordada desde diferentes planes y programas educativos a propuesta de organismos educativos, integrando en los proyectos educativos de centro acciones paliativas de cara a reducir el riesgo de abandono.

\section{REFERENCIAS BIBLIOGRÁFICAS}

Alegre Canosa, M. A. y Subirats i Humet, J. (2013). Sistemas y políticas educativas comparadas: transformaciones, convergencias y divergencias en los países occidentales, en Del Pino, E. y Rubio, J. (ed.), Los estados de bienestar en la encrucijada, (262-290). Tecnos.

Alemany, I., Rojas, G., Gallardo, M. A. y Sánchez, S. (2013). El abandono escolar temprano en un contexto multicultural. Análisis de sus causas por los agentes profesionales y sociales implicados. Journal for Educators, Teachers and Trainers, 4(2), 191-203. 
Aramendi Jaúregui, P. y Vega Fuente, A. (2013). Los Programas de Cualificación Profesional Inicial. La perspectiva del alumnado del País Vasco. Revista de Educación, $360,436-460$.

Barca Lozano, A., Regina Pesutti, C., Brenlla Blanco, J. C. y Santamaria Canoso, S. (2000). Enfoques de aprendizaje, estilos atribucionales y rendimiento académico en una muestra de alumnos de educación secundaria de Brasil. Revista galego portuguesa $\begin{array}{lllll}\text { de psicología educación, } & \text { 6 } & \text { 769-791. }\end{array}$ https://dialnet.unirioja.es/servlet/articulo?codigo $=1049258$

Belfield, C. (2008). The Cost of Early School-leaving and School Failure. Research prepared for the World Bank. [Archivo PDF]. http://siteresources.worldbank.org/INTLACREGTOPPOVANA/Resources/BEL FIELDCostofSchoolFailure.pdf

Benchimol, K., Krichesky, G. y Piogré, P. (2011). ¿Por qué no están en la escuela? Modos de exclusión instrumental e incidentes críticos que empujaron a jóvenes de la provincia de Buenos Aires a dejar la escuela. Revista de Currículum y Formación del Profesorado, 15, 3-10.

Bing Tan, P. J. (2013). Applying the UTAUT to Understand Factors Affecting the Use of English E-Learning Websites in Taiwan. SAGE Journals 3(4). https://doi.org/10.1177\%2F2158244013503837

Calero, J. y Escardíbul, J. O. (2007). Evaluación de servicios educativos: El rendimiento en los centros públicos y privados medido en PISA 2003. Hacienda Pública Española, 183(4), 33-66.

Calero, J., Choi, A. y Waisgrais, S. (2010). Determinantes del riesgo de fracaso escolar en España: una aproximación a través de un análisis logístico multinivel aplicado a PISA-2006. Revista de Educación, número extraordinario 3, 225-256.

Camacho Ruiz, M. A. (2018). Fracaso escolar y abandono educativo temprano en Huelva. Prácticas en positivo y propuestas de mejora. [Archivo PDF] https://www.unia.es/explorar-catalogo/item/fracaso-escolar

Carrasco, S., Narciso, L., Bertran, M. (2015). ¿Qué pueden hacer los centros públicos ante el abandono escolar prematuro? Revista de Currículum y Formación de Profesorado, 19(3) 76-92. http:// www.redalyc.org/articulo.oa?id=56743410006

Cerda Navarro, A., Sureda García, I. y Salvá Mut, F. (2020). Intención de abandono y abandono durante el primer curso de Formación Profesional de Grado medio: Un análisis tomando como referencia el concepto de implicación del estudiante. Estudios sobre Educación, 39, 35-57. 
Chen, S. C. y Dhillon, G. S. (2003). Interpreting Dimensions of Consumer Trust in ECommerce. Information Technology and Management, 4 (2), 303-318.

Choi de Mendizábal, Á. B. y Calero, J. (2013). Ideas para superar el fracaso escolar en España: Análisis y propuestas de futuro. Documentos de debate. Fundación Ideas.

Clemente Martos, A. (2010). La orientación educativa frente al abandono escolar, Revista Digital de Educación y Experiencias Educativas, 37, 1-10. http://www.csicsif.es/andalucia/modules/mod_ense/revista/pdf/Numero_37/ANTONIA_CL EMENTE_1.pdf

Constante Amores, A., Florenciano Martínez, E., Navarro Asencio, E. y FernándezMellizo, M. (2021). Factores asociados al abandono universitario. Educación XX1, 24 (1), 17-44. http://doi.org/10.5944/educXX1.26889

Dávila, J. C. (2010). Sobre el sueño y su necesidad. Encuentros en la biología, 3(131), 6769.

Ecoaula. (2021). Cerca del 90\% del personal educativo relaciona el abandono escolar con el sistema de evaluación por notas. [Archivo PDF] https://www.eleconomista.es/ecoaula/noticias/11084315/03/21/Cerca-del-90del-personal-educativo-relaciona-el-abandono-escolar-con-el-sistema-deevaluacion-por-notas.html

Ekstrand, B. (2015). What it takes to keep children in school: a research review. Educational Review, 67(4), 459-482. http://doi.org/http://dx.doi.org/10.1080/00131911.2015.1008406

Esch, P., Bocquet, V., Pull, C., Couffignal, S., Lehnert, T., Graas, M. y Ansseau, M. (2014). The downward spiral of mental disorders and educational attainment: a systematic review on early school leaving. BMC Psychiatry, 14(1), 2-13. http://doi.org/10.1186/s12888-014-0237-4

Europan Commisión, 2020. Europe 2020 targets: statistics and indicators for Spain. https://ec.europa.eu/info/business-economy-euro/economic-and-fiscal-policycoordination/eu-economic-governance-monitoring-preventioncorrection/european-semester/european-semester-your-country/spain/europe2020-targets-statistics-and-indicators-spain_en

González Pienda, J. A. (2003). El rendimiento escolar. Un análisis de las variables que lo condicionan. Revista galego-portuguesa de psicoloxía e educación, 7 (8), 247-258.

González, D., Vieria M. J. y Vidal, J. (2019). La percepción del profesorado de Educación Primaria y Educación Secundaria sobre las variables que influyen en el abandono escolar temprano. Revista de Investigación Educativa, 37 (1), 181-200. 
Haneshek, E. (2006). School Resources. Handbook of the Economics of Education, 2, 865908.

Hernández García, A. (2011). Desarrollo de un modelo unificado de adopción del comercio electrónico entre empresas y consumidores finales. A plicación al mercado español. [Tesis de maestría, Universidad Politécnica de Madrid. Departamento de ingeniería de organización, administración de empresas y estadística] http://oa.upm.es/10281/

Hernández Prados, M. A. y Alcaraz Rodríguez, M. (2018). Factores incidentes en el abandono escolar prematuro. Revista de investigación en educación, 16(2), 182-195.

Holgueras, A. I. (2016). Análisis de la influencia de la orientación profesional en los jóvenes en situación de abandono escolar. Educación Siglo XXI, 34(1), 137-159. http://dx.doi.org/10.6018/j/253251

Holmlund, H., McNally, S. y Viarengo, M. (2010) Does money matter for schools? Economics of Education Review, 29(6) 1154-1164.

Instituto Nacional de Estadística (INE) 2020. Tasa de abandono escolar temprano https://www.ine.es/jaxiT3/Tabla.htm?t=12543

Krueger, A. y Whitmore, D. (2001). Would Smaller Classes Help Close the BlackWhiteAchievement Gap? Working Paper 451.

López Becerra, F. (2011). Relación entre el hábito de consumo de videojuegos y el rendimiento académico. International Journal of Developmental and Educational Psychology, 1(2), 347-356. https://dialnet.unirioja.es/servlet/articulo? codigo $=5417930$

López Hernández, F. A. y Silva Pérez, M. M. (2016). Factores que inciden en la aceptación de los dispositivos móviles para el aprendizaje en educación superior. Estudios sobre educación. 30, 175-195. https:/ / doi.org/10.15581/004.30.175-195

Mancebón, M. J., Calero, J., Choi, A. y Ximénez de Embún, D. P. (2012). The efficiency of public and publicly subsidised high schools in Spain: Evidence from PISA 2006. Journal of the Operational Research Society, 63(11), 1516-1533.

Marchesi, A. (2003). El fracaso escolar en España. Fundación Alternativas.

Martín, M. y Luna, F. (2016). Volver a estudiar en tiempos de crisis. Cuadernos de Pedagogía, 426, 16-23.

Martinez-Otero, Pérez, V. (2009). Diversos condicionantes del fracaso escolar en la educación secundaria. Revista iberoamericana de educación, 51, 67-85. 
Mena Martínez, L., Fernández Enguita, M. y Rivière Gómez, J. (2010). Desenganchados de la educación: procesos, experiencias, motivaciones y estrategias de abandono y del fracaso escolar. Revista de educación, número extraordinario, 1, (5), 119-145.

Michel Madera, M., Torres Nabel, L. C. y Quevedo Huerta, L. N. (2012). Estudio de traducción y confiabilidad del instrumento de la Teoría Unificada de la Aceptación y Uso de la Tecnología (UTAUT). Apertura, 4(2). http://www.udgvirtual.udg.mx/apertura/index.php/apertura/issue/view/52

Montes, A. y Parcerisa, L. (2016). ¿Iguales en qué y cómo? Una revisión de las propuestas realizadas desde la teoría de la justicia al campo de la educación. Papers 101 (4) http://dx.doi.org/10.5565/rev/papers.2194 451

Mora Corral, M. J. (2010). Determinantes del abandono escolar en Cataluña. Más allá del nivel socioeconómicos de las familias. Revista de educación, 1(extra), 171-190. https://dialnet.unirioja.es/servlet/articulo?codigo $=3342426$

Moreno, T. (2010). La relación familia-escuela en secundaria: algunas razones del fracaso escolar. Profesorado. Revista del Curriculum y Formación del Profesorado, 14(2), 240-255.

Nevala, A. M. y Hawley, J. (2011). Reducing early leaving from education and training in the EU. Brussels: Parlamento Europeo. [Archivo PDF] https://www.europarl.europa.eu/RegData/etudes/etudes/join/2011/460048/IP OL-CULT_ET\% 282011\%29460048\%28SUM01\%29_EN.pdf

Navalón Mira, A., Ruiz Callado, R. (2017). Consumo de sustancias psicoactivas y rendimiento académico. Una investigación en estudiantes de secundaria $\begin{array}{llllll}\text { obligatoria. } & \text { Salud } & y & \text { drogas, } & 17(1) & 45-52 .\end{array}$ http://www.redalyc.org/articulo.oa?id=83949782005

Oye, N. D. A., Iahad, N. y Ab.Rahim, N. (2014). The history of UTAUT model and its impact on ICT acceptance and usage by academicians. Educ Inf Technol 19, 251-270 https://doi.org/10.1007/s10639-012-9189-9

Pérez Gómez, A. I. (2012). Del sujeto epistémico al sujeto digital. Con-Ciencia Social, 18, 71-85.

Pérez Esparrells, C. y Morales Sequera, S. (2012). La descentralización de la enseñanza no universitaria en España: análisis de convergencia desde la perspectiva del gasto. Presupuesto y Gasto Público 67, 137-160.

Psacharopoulos, G. (2007). The Costs of School Failure -A Feasibility Study. Analytical Report prepared for the European Commission. [Archivo PDF] http://www.eenee.de/portal/page/portal/EENEEContent/_IMPORT_TELECE NTRUM/DOCS/EENEE_AR2.pdf

Vivat Academia. Revista de Comunicación. 2021, nº 154, 25-52 
Raza, S. A., Qazi, V. y Kahn, K. A. (2020). Social Isolation and Acceptance of the Learning Management System (LMS) in the time of COVID-19 Pandemic: An Expansion of the UTAUT Model. Journal of Educational ComputingResearch 0(0) 1- 26. https://journals.sagepub.com/doi/pdf/10.1177/0735633120960421

Rizo, L. J. y Hernández, C. (2019). El fracaso y el aband ono escolar prematuro: el gran reto del sistema educativo español. Papeles salmantinos de educación, 23, 55-81.

Rodríguez-Pineda, M. y Zamora, J. A. (2021). Abandono temprano en estudiantes universitarios: un estudio de cohorte sobre sus posibles causas. Revista Uniciencia. 35(1).https://dx.doi.org/10.15359/ru.35-1.2

Sánchez Alhambra, A. (2017). Aspectos académicos y personales que inciden en el abandono escolar temprano en Educación Secundaria Obligatoria. [Tesis de maestría, Universidad Complutense de Madrid Departamento de Didáctica y Organización Escolar]. https://eprints.ucm.es/42407/1/T38717.pdf

Salloum, S. A., y Shaalan, K. (2019). Factors Affecting Students' Acceptance of ELearning System in Higher Education Using UTAUT and Structural Equation Modeling Approaches. En Hassanien A. E., Tolba M. F., Shaalan K. y Azar A. T. (Ed). Proceedings of the International Conference on Advanced Intelligent Systems and Informatics. 469-480. Springer, Cham https://doi.org/10.1007/978-3-319-99010$\underline{1 \_43}$

Sauquillo, P. y Bellever, M. C. (2008). El rol de género en los videojuegos. Teoría de la Educación. Educación y Cultura en la Sociedad de la Información. 9(3) 130-149.

Subirats, J. (2006). ¿Quién educa? Fracaso escolar y responsabilidades compartidas. Algunas notas para el debate sobre educación y entorno. Congrés Anual sobre fracàs escolar. [Archivo PDF]. http://www.fracasoescolar.com

Taylor, S. y Todd, P. (1995). Decomposition and crossover effects in the theory of planned behavior: A study of consumer adoption intentions. International Journal of Research in Marketing, 12 (2), 137-155.

UNESCO (2012). Educación para todos. [Archivo PDF]. [http://www.unesco.org/new/es/our-priorities/education-for-all/

Vaillant, D. y Marcelo, C. (2015). El ABC y D de la formación docente. Madrid: Narcea.

Ventakesh, V., Morris, G., Davis, G. y Davis, F. (2003). User acceptance of information technology: Toward an unified view. MIS Quarterly, 27 (3), 425-478. 
Venkatesh, V. y Davis, F. D. (2000). A Theoretical Extension of the Technology Acceptance Model: Four Longitudinal Field Studies. Management Science, 46 (2), 186204. https://doi.org/10.1287/mnsc.46.2.186.11926.

West, M. R. y Woessmann, L. (2010). Every catholic child in a catholic school: historical resistance to state schooling, contemporary school competition, and student achievement across countries. The Economic Journal, 120, 229-255.

\section{AUTOR:}

\section{Iratxe Suberviola Ovejas}

Licenciada en Psicopedagogía, y Diploma de Estudios Avanzados en Didáctica y Organización Escolar. Máster en e-learning y tecnología educativa. Profesora contratada interina de la Universidad de La Rioja en el Departamento de Educación, área de didáctica y organización escolar. Perteneciente al grupo de investigación y Igualdad y género de la Universidad de la Rioja e investigadora del Instituto de Estudios Riojanos. Formadora de la Consejería de Educación de la Comunidad de La Rioja al profesorado de Educación Primaria y Educación Secundaria.

Orcid ID: https:// orcid.org/0000-0001-6368-3732

Google Scholar: https://scholar.google.es/citations?user=b4EeVfsAAAAJ\&hl=es 